\title{
Disability rights and mental health in the UK: recent developments of the Disability Discrimination Act
}

\author{
Liz Sayce \& Jed Boardman
}

\begin{abstract}
The Disability Discrimination Act, passed by Parliament in 1995 and amended in 2001 and 2005, covers people in Britain with physical or mental impairments that have a substantial and long-term adverse effect on their ability to carry out normal day-to-day activities. The Act has been important in setting a framework for good practice and it can stimulate more systemic change through formal investigations of organisations or whole sectors, and through the Disability Equality Duty, in force since December 2006. The Disability Discrimination Act has implications for people working in mental health services when they are considering employment and educational opportunities for service users, and when they are considering how to redress systemic disadvantage, including inequalities in physical health.
\end{abstract}

It is well established that many people with mental health problems experience discrimination and social exclusion in a range of life domains (Social Exclusion Unit, 2004). For example, they are much less likely to be in employment than other members of the general population (Boardman, 2003), more likely to experience family poverty (Disability Rights Commission, 2007a) and more likely to die young of major physical health problems (Disability Rights Commission, 2006b). Such considerations concern not only the preservation of health and well-being but also rights and social justice (Ikkos et al, 2006).

The attainment of meaningful occupation is an important provision in facilitating the inclusion of people with mental illness in broader society. Work contributes to our physical and mental wellbeing and has particular relevance for those with psychiatric disabilities (Waddell \& Burton, 2006). Assisting people with mental disorders to retain or gain work is a key part of the rehabilitative efforts of mental health services. Mental health professionals and others tend to underestimate the capacities and skills of their clients and possibly overestimate the risk to employers. It is thus important that we have knowledge not just of assessments for work and the available facilities but also of the legislation that may affect employment.
In Britain, the most significant legislation in terms of promoting increased employment opportunity is the Disability Discrimination Act 1995. Other relevant law is listed in Box 1. The government has also introduced regulations debarring employment discrimination on grounds of age, religion/belief and sexual orientation; in addition, it has commissioned and published an Equalities Review (Cabinet Office, 2007), reviewing evidence and analysis on equality in Britain, and a Green Paper (Department for Communities and Local Government, 2007) in

Box 1 Other relevant legislation

Relating to employment opportunity

- Health and Safety at Work Act 1974

- Human Rights Act 1998

- Race Relations Act 1976

- Race Relations (Amendment) Act 2000

- Sex Discrimination Act 1975

- Equality Act 2006

Relating to employment and reports

- Access to Medical Reports Act 1988

- Access to Health Records Act 1990

- Data Protection Act 1998

Liz Sayce is Chief Executive of RADAR (the Royal Association for Disability and Rehabilitation), based in London, and a member of the UK Commission for Employment and Skills and the Disability Committee of the Equality and Human Rights Commission. Previous posts include Director of Policy and Communications with the Disability Rights Commission and Policy Director with Mind. She was a member of the government's Disability Rights Task Force 1997-1999. Jed Boardman is a consultant psychiatrist with the South London and Maudsley NHS Foundation Trust (Lordship Lane Community Mental Health Team, 20-22 Lordship Lane, London SE22 8HN, UK. Email: jedboard@atlas.co.uk) and a senior lecturer in social psychiatry in the Health Service and Population Research Department at the Institute of Psychiatry, London. He was Chair of the Royal College of Psychiatrists' Working Group on Employment Opportunities for People with Psychiatric Disabilities. He is now Chair of the College's Social Inclusion Scoping Group. 
advance of the Single Equality Bill, to bring coherence and consistency to equalities legislation (www. communities.gov.uk).

Mental health professionals are well placed to enable people with mental health problems to secure opportunities in education, access to goods and services, and involvement in community and family life, matters also covered by the Act.

We first wrote for APT on the Disability Discrimination Act in 2003 (Sayce \& Boardman, 2003), and here we examine the progress of the Act over the intervening 5 years, the amendments made in 2005 and areas requiring further changes. We also outline the formal investigation carried out by the Disability Rights Commission on physical health inequalities. A new Single Equalities Bill is expected in 2008 that may further amend the law.

\section{Disability Discrimination Act 1995}

The Disability Discrimination Act was originally passed in 1995 (Box 2). Mental health problems, current and recovered, ranging from schizophrenia and bipolar affective disorder (manic depression) to panic disorders and depressive conditions are potentially within the scope of the Act. A more complete explanation of the Act and its implications for psychiatrists can be found in our earlier article (Sayce \& Boardman, 2003).

The Disability Rights Commission was established in 2000 to promote and enforce the Act, with the ultimate aim of eliminating discrimination and increasing equality of opportunity. In October 2007, the Disability Rights Commission and similar bodies covering race and gender (Commission for Racial Equality, Equal Opportunities Commission) were replaced by the Equality and Human Rights Commission (see below), which covers race, gender, disability, sexual orientation, age and religion/belief as well as human rights (HM Government, 2004). The new Commission has set itself the goal of creating a nation that is at ease with its diversity.

\section{The disability rights movement and mental health matters}

The British disability movement has campaigned for improved rights for disabled people over several decades and has raised awareness through documenting the extent of discrimination (Barnes, 1991), parliamentary lobbying and direct action. Although the disability movement was led primarily by people with physical and sensory impairments, the disability rights paradigm has been effectively used, in Britain and internationally, to challenge discrimination on mental health grounds (Sayce,
2000). Central to the argument is the 'social model' of disability (Oliver, 1990), which locates the problems faced by disabled people not in their impairments per se, but in the disabling effects of barriers in the social, economic and physical environment. Prejudice and barriers to employment form an important part of this picture.

The Disability Discrimination Act explicitly covers people with mental impairments. This includes many with mental health problems as well as those with intellectual disability (commonly referred to as learning disabilities by the government and service providers in the UK). The Act has allowed people with mental disorders to seek legal redress for discrimination. For example, $23 \%$ of all employment cases brought under the Act by 2002 related to people facing discrimination because of their mental illness or impairment. Weaknesses in the law resulted in the dismissal of a substantial proportion of these, but in a number of high-profile cases individuals have secured redress (Sayce \& Boardman, 2003).

The Disability Discrimination Act has been influential in the setting of fairer policies and the stimulation

\section{Box 2 Summary of the Disability Discrimina- tion Act 1995}

- Covers protection from discrimination for disabled people in the areas of:

- employment (Part II)

- provision of goods, services and facilities (Part III)

- education (Part IV)

- transport (Part III)

- Makes it unlawful in these areas to treat someone 'less favourably' for a reason related to their disability

- The definition of a disabled person is someone 'with a physical or mental impairment that has a substantial and long-term adverse effect on their ability to carry out normal day-to-day activities'

- Employers are required to identify obstacles to employment and to make 'reasonable' adjustments to overcome these

- It is unlawful not to make adjustments to enable a person to use services unless to do so would be 'unreasonable'

- Public, private and voluntary sector service providers of all sizes are covered (including general practitioner surgeries, the NHS, local authorities)

- Protection from discrimination in education covers early years, primary and secondary schooling, colleges and universities, and life-long learning 
of good practice. For example, the Act made unlawful the '2-year rule', the blanket exclusion from nursing and other professions of individuals who had received psychiatric treatment in the preceding 2-year period (Department of Health, 2002).

Some bridge-building has occurred between mental health groups and the wider disability movement. The Disability Rights Commission's Mental Health Action Group has produced two documents designed to place mental health centre stage within disability rights (Disability Rights Commission, 2003a) and within the broader equality and human rights agenda (Disability Rights Commission, 2007a,b). None the less, there is evidence of prejudice against people with mental health problems by people with other types of disability (Department for Work and Pensions, 2003) and some in the mental health community remain cautious about the links with other disability groups.

At the same time, policy makers have become increasingly interested in social inclusion, and therefore removing discriminatory barriers, for people with mental health problems. The government has set a target of $80 \%$ employment in Britain and if this is to be achieved it has to engage with those furthest from the labour market (Freud, 2007) and reduce discrimination by employers (only $37 \%$ of employers in 2001 reported that they would employ someone with a mental health problem; Bunt et al, 2001). Since $40 \%$ of those on incapacity benefit have a mental health problem as their primary impairment - rising to $60 \%$ if secondary impairments are included (HM Government, 2006) - the issue of rights to inclusion of people with mental health conditions has suddenly moved from the periphery of disability rights policy to a central position in employment policy.

In 2007 the Disability Rights Commission published its Disability Agenda (Disability Rights Commission, 2007a). This pointed out that a number of challenges facing Britain (increasing people's skills, and reducing child poverty and health inequalities) can be effectively addressed only by attending to people with disabilities (including mental health conditions) from the outset in policy and delivery. In many key policy areas, people with mental health problems face particular disadvantages. This may be seen in the area of child poverty, which is currently a major priority for the government. Although the overall employment rate for disabled people who have children is about $52 \%$, there are considerable variations between the types of disability; for example, for parents with disabling skin conditions or allergies the employment rate is $71 \%$, whereas for those with depression and 'nerves' it is $23 \%$ and for people with serious mental illness only $10 \%$. Such statistics emphasise the need for the government and the Equality and Human Rights Commission to accept that disability must be given a clear emphasis in major policy developments and priority must be given to people with mental health problems.

\section{The 2005 amendments to the Act}

The Disability Discrimination Act was amended in 2001 (to cover education) and 2005; regulations were passed in 2003. In April 2005, a new Disability Discrimination Act was passed by Parliament, which amended or extended the provisions of the 1995 Act (Box 3). Two important changes that have particular significance for people with mental health problems are, first, the removal of the requirement that they prove that their condition is 'clinically well recognised' and, second, the introduction of the Disability Equality Duty.

\section{The 'clinically well-recognised' requirement}

Under the original 1995 legislation, mental health service users (unlike people with physical impairments) had to demonstrate that they had a clinically well-recognised condition. The reason for this was that the law was not intended to cover 'moods or mild eccentricities'. Case law showed that conditions

\section{Box 3 The Disability Discrimination Act:} amendments in 2005

- Extended Part III of the 1995 Act to cover transport systems, making it unlawful for operators of transport vehicles to discriminate against disabled people

- Extended to rented property, making it easier for disabled people to rent property and for tenants to make disability-related adaptations

- Extended protection to cover people with HIV/AIDS, some forms of cancer and multiple sclerosis from the time of diagnosis

- Extended the discrimination laws to cover all activities of the public sector

- Extended coverage to all private clubs with 25 or more members

- Makes it an offence for a third party, such as a newspaper, to publish an advert (such as a job advert) that is discriminatory against disabled people

- Requires public bodies to promote equality of opportunity for disabled people (Disability Equality Duty)

- Removed the requirement of people with mental health conditions to prove that their condition was 'clinically well recognised' 
found to be clinically well recognised for this purpose included schizophrenia, clinical depression, clinical anxiety, bipolar affective disorder, agoraphobia, posttraumatic stress disorder and bulimia nervosa.

It was not necessary to look at the causes of the illness to demonstrate that someone was disabled. In Power v. Panasonic UK Ltd [2003] the Employment Appeal Tribunal judged that the fact that Ms Power's depression may have been caused by alcohol misuse did not alter the fact that she could be held to be disabled. Even so, the 'clinically well-recognised' requirement was an extra hurdle to clear in order to qualify for rights. There were some cases in which disagreement over diagnosis between different psychiatrists was used in tribunals to argue that a condition was not clinically well recognised (since there was no clinical consensus). The requirement also placed discrimination at the heart of the law, since it applied only to people with mental illness, not other types of disability. In 2005, the government abolished this requirement outright in a symbolically significant move to promote the equality of mental health service users.

\section{The Disability Equality Duty}

In 2005 the government legislated for a positive Disability Equality Duty (in force since December 2006). This new legal duty requires public sector organisations (which include schools and colleges, NHS trusts, libraries, police forces, central and local government) to promote equality positively and proactively by involving people with disabilities, drawing on evidence to create action plans to achieve equality and promoting positive attitudes. Major (listed) public sector organisations have to publish a 'disability equality scheme', which must include a statement of how disabled people have been involved in developing the scheme, an action plan that includes practical ways in which improvements will be made, and the arrangements in place for gathering information on meeting targets on disability equality.

The Statutory Code of Practice on the Disability Equality Duty suggests that public sector organisations can prioritise remedial action in relation to groups facing particular exclusion. For instance, a mental health NHS trust could take active steps to recruit people with mental health problems as part of their core business of remedying social exclusion and promoting employment opportunities for people with mental health problems.

Guidance on monitoring under the Disability Equality Duty advises that organisations should consider monitoring (e.g. of employment and service outcomes) by broad impairment group: mental health problems, sensory impairments, intellectual disability, physical impairments or long-term health conditions. This means that the disparities between impairment groups - as well as between disabled people overall and non-disabled - will be revealed, offering more scope to take and monitor action over time. This is an important step forward from the more generic approach to 'disability rights' previously in vogue, which suggested that people were disabled by the society around them and that the nature of their impairment was insignificant.

The full potential of the Disability Equality Duty cannot yet be assessed. At best it could mean that a government introducing new policy on, for example, skills, would factor in the requirements and interests of people with disabilities (including mental health service users) from the outset, and delivery agencies would ensure effective implementation across the spectrum of disability. The Disability Equality Duty - with its requirements for involvement of disabled people, use of evidence and action planning - would be the mechanism to ensure that this mainstreaming takes place. The expected Single Equalities Bill may change the Disability Equality Duty to align it with legislation in other areas of equality.

\section{The Commission for Equality and Human Rights}

The Equality and Human Rights Commission was established through the Equality Act 2006. It has three main pillars: equality, human rights and good relations. On equality, the Commission will have powers similar to those of the Disability Rights Commission and will promote and monitor the Disability Equality Duty. The government is committed to single equality legislation, designed to bring coherence to equalities legislation. This is likely to mean that the Equality and Human Rights Commission will in time be tasked with promoting positive equality duties covering all six areas (gender, race, disability, sexual orientation, age and religion/ belief). It is also tasked with promoting human rights, which could encompass issues such as rights to dignity, privacy and family life, for example, in health and social care facilities. Finally, it will promote good relations between groups and communities. Although this has been largely discussed in relation to ethnic and faith communities it might be applied, for example, to countering nimby -'not in my back yard' - campaigns.

\section{Development of the Act: limitations and progress}

In the early years of implementation of the Disability Discrimination Act it was clear that attitudes towards employing people with disabilities and employment 
practices were improving. This is beginning to apply to those with psychiatric as well as physical impairments (Employers' Forum on Disability, 1998). The proportion of employers with disability policies rose from just over 65\% in 2001 to $90 \%$ in 2002 (Equal Opportunities Review, 2002). By 2005 almost all (95.3\%) of the employing organisations surveyed said that they had a formal policy on disability, typically as part of a wider equality or diversity policy (Egan, 2005). Between 2001 and 2002, employers stating that they employ people with disabilities or long-term health problems rose from $87 \%$ to $95 \%$ and reasons for this included both a commitment to corporate social responsibility and Disability Discrimination Act compliance (Equal Opportunities Review, 2002). Employers are increasingly allowing absence for rehabilitation and treatment (cited by eight out of ten employers), acquiring or modifying equipment, altering individual working hours, assigning a person to other work and providing flexible working arrangements (Egan, 2005).

Although the Act contains examples of expected adjustments (Box 4), the list is not comprehensive and companies often need to take advice about the type and reasonableness of adjustments they can be required to make (Employers' Forum on Disability, 1998). For people with mental health problems such adjustments might include greater supervision, regular meetings with supervisors/managers, and mentor support. More supporting evidence is needed and it might be useful to apply more imagination to the types of reasonable adjustment that could be recommended. We are aware of adjustments in practice ranging from changed hours (to avoid

Box 4 Steps that an employer may have to take in employing a disabled person

- Making adjustments to premises

- Allocating some of the disabled person's duties to another person

- Transferring him or her to fill an existing vacancy

- Altering working hours

- Assigning to a different place of work

- Allowing absence during working hours for rehabilitation, assessment or treatment

- Giving, or arranging, training

- Acquiring or modifying equipment

- Modifying instructions or reference manuals

- Modifying procedures for testing or assessment

- Providing a reader or interpreter

- Providing supervision

(Disability Discrimination Act 1995, Part II) rush-hour travel) to steadier shift patterns (to fit medication effects).

The Royal Association for Disability and Rehabilitation (2007) has developed a guide that documents what disabled people have found helpful in managing their impairment and their employment. This might be the first in a bank of such examples.

The rate of employment among people with longterm mental health problems went up from $15 \%$ in 1998 to $20 \%$ in 2005 - still very low, but showing a modest rise.

\section{The law in practice}

The terms 'disability access' and 'disability equality' conjure up visions of ramps, lifts and redesigns of the physical environment. This is a misunderstanding of current legislation. Access and equality for people with disabilities goes far beyond the physical environment. Adjustments required include changes in service systems, schools, colleges and workplaces of direct benefit to mental health service users, people with long-term health conditions such as kidney disease, those with intellectual disability and more.

\section{Case example 1: Ms Beart}

Ms Beart worked for the prison service. She had depression and was sacked while on sick leave. She argued that the prison service had failed to make a reasonable adjustment - namely to relocate her in line with medical advice. Her claim of disability discrimination was successful and she was awarded around half a million pounds in compensation for lost earnings (http: / / 83.137.212.42/sitearchive/DRC/ the_law.html).

In education there have been a few important cases concerning making adjustments in schools and universities, including requiring a university to provide accommodation on campus for someone with mental health-related difficulties in travelling. In goods and services there have been limited successful legal challenges in housing (by stopping evictions) and insurance (by stopping blanket exclusion of people with mental health problems, though insurers will still generally only pay out for situations unrelated to pre-existing conditions or will load premiums) (see http:/ /83.137.212.42/ sitearchive/DRC/index.html).

Mental health employment cases have continued to be lost and won.

\section{Case example 2: Mr Paul}

Mr Paul had long-term depression. He applied for two part-time jobs with the probation service - a community service supervisor and a handyman. He was offered the handyman post but turned down for the supervisor post on the grounds that it was thought too stressful for him. This decision was made without 
consulting him, his psychiatrist or the organisation with which he had successfully been volunteering for some years. He took a Disability Discrimination Act case and won. The Employment Appeal Tribunal ruled that the employer could have scrutinised the occupational health assessment with more care, obtained specialist advice from Mr Paul's consultant, spoken further with Mr Paul himself, and looked at adjustments to the job to enable Mr Paul to do it (http:/ /83.137.212.42/ sitearchive/DRC/the_law.html).

This ruling showed that a blanket ban on the basis of diagnosis - and the assumption that depression meant he could not do this job - was not acceptable. The probation service was instructed to offer Mr Paul the next available suitable vacancy and he therefore obtained the work he wanted as a community service supervisor.

In 1995, a MORI poll found that the public was most likely to accept people with mental illness as roadsweepers, actors, comedians or farm workers, and least likely to accept them as doctors, child-minders, police officers or nurses. It seems that 'madness' coexists in the public mind with the most menial and the most creative jobs but not with jobs requiring responsibility (Mind, 1998), thus perhaps driving the decision that someone with depression can be an oddjob man but not a supervisor. Nevertheless, prominent decision-makers from Winston Churchill to Alistair Campbell have had mental health problems and the law is beginning to catch up with this reality.

Other cases have extended the interpretation of the law.

\section{Case example 3: Mr Hewett}

Mr Hewett challenged Motorola, claiming that they had discriminated against him in an assessment of his performance and failed to make reasonable adjustments. The original tribunal decided that his impairments related to Asperger syndrome - did not constitute a disability under the Disability Discrimination Act. The Employment Appeal Tribunal, however, reversed that ruling on the grounds that his impairment had an adverse impact on his ability to understand (one of the list of day-to-day activities listed under the Act), which should cover understanding of broad human social interaction. A decision that someone with difficulties in social interaction is covered by antidiscrimination law is potentially very helpful for mental health service users (http:/ /83.137.212.42/sitearchive/DRC/the_law. html).

Under the Disability Discrimination Act it is not legal to require that someone holds a current driving license if it is not integral to their work role, as this could discriminate against (for instance) someone with epilepsy (www.epilepsy.org.uk). This ruling could also be useful for people unable to drive owing to the effects of psychiatric medication.

A House of Lords case involving a mental health service user and others (Jones (Appellant) v. 3M
Healthcare Limited (Respondents) and three other actions [2003]) established that discrimination is illegal even after a person has left the job (for instance, in the provision of references).

\section{Legal developments: weakness and reforms}

There were weaknesses in the law - some but not all of which have been addressed through progressive reforms.

\section{Time period for defining disability}

Case example 4: care worker

A man was offered a job as a care worker by a local authority. He had a history of mental health problems, but did not disclose that fact on a medical questionnaire. Between accepting the job and starting work, he experienced a severe episode of depression. When the local authority found out, the offer of employment was withdrawn, notwithstanding the view of the local authority's occupational health officer that the client was fit for work. The client brought a disability discrimination claim and lost because the tribunal found that his depression did not have a substantial and long-term adverse effect on his ability to carry out normal day-to-day activities (http://83.137.212.42/ sitearchive/DRC/the_law.html).

The case of the care worker described above reveals a continuing weakness in the Disability Discrimination Act. If someone is not quite 'disabled enough' to qualify for protection under the Act, they can still be viewed by an employer as too 'disabled' to do a job and therefore refused work. If they have not been disabled long enough to be covered by the Act and cannot demonstrate that they are likely to remain disabled for 12 months, they can still be viewed by the employer as a risk of presenting long-term recurrent problems - and refused work. This leaves people in a 'catch 22' situation and means that employers are free to discriminate, paradoxically, against people who do not have major impairments (so why allow them to be refused jobs?).

Disability and mental health organisations have lobbied for different approaches to overcome this barrier to justice. One approach is to change the time limit, so that people with, for example, depression would be covered if the depression had lasted or was likely to last for 6 months: lobbying for this was unsuccessful in 2004-2005. Another is to make any discrimination on disability/mental health grounds illegal, irrespective of how 'disabled' the person is, thereby removing the first challenge in taking a case - proving you are disabled in the meaning of the Act. This was discussed by the Disability Rights 
Task Force in 1997-1999 and rejected by Ministers and some disability organisations, but has now been promoted by the Disability Rights Commission; it has not yet been implemented (Disability Rights Commission, 2006a).

\section{Demonstrating disability}

The definition of disability and list of day-to-day activities used to demonstrate disability are skewed towards physical impairment, making it harder for mental health service users to show that they are disabled under the law. The list includes a variety of physical activities - such as walking and seeing - and a smaller number of mental health-related activities involving memory and ability to concentrate. The Disability Rights Commission argued that this list should be extended to provide improved coverage for mental health service users (Disability Rights Commission, 2003b). This priority for reform may be addressed through the expected Single Equalities Bill.

\section{Justified discrimination}

The case of Ms Marshall (Sayce \& Boardman, 2003) sent shock waves through the mental health and disability rights community. Ms Marshall, a highly talented young women with a Cambridge degree and strong work record, was offered a job as a finger-printing officer with a police force only to have the offer withdrawn when her diagnosis of bipolar affective disorder came to light in a preemployment occupational health check. Although she won her tribunal case, this was overturned on appeal, on the grounds that the employer had sought occupational health advice and could not be held responsible for the quality of that advice. This decision was possible because tribunals had (since the important non-mental health case Jones $v$. Post Office [2001]) started taking narrow decisions on employers' responsibilities. In short, as long as they obtained occupational health advice (even poor advice) from a suitably qualified person, and as long as this produced an answer 'which was not irrational', the tribunals could not disagree with the risk assessment the employer reached. Employers could justify discrimination and were very readily seen as complying with their obligations. In one case (Morgan v. Staffordshire University [2002]) the Employment Appeal Tribunal judgment stated that 'the tribunals are not inquisitorial bodies charged with a duty to see to the procurement of adequate medical evidence'.

However, in 2004 regulations were implemented under the Disability Discrimination Act which were in line with European requirements: direct employment discrimination became unlawful; it could no longer be justified. The new Code of Practice states that it is unlawful for an employer to reject someone without proper consideration of the impact of the particular person's disability on whether they could do the particular job. Having obtained occupational health advice is no longer a justification for refusing someone a job. It is likely that the Marshall decision would have been different, had it been made after 2004 .

Since 2004, other Disability Discrimination Act employment cases (beyond mental health), in the Appeals Courts and House of Lords, have started to expand the agreed responsibilities of the employer from the baseline of Jones $v$. The Post Office [2001]. For instance, the cases of Meikle v. Nottinghamshire County Council [2005], and of Archibald v. Fife Council [2004], demonstrate that reasonable adjustments have to be made, including offering someone a higher-graded post, if suitable, if impairment means that they can no longer do the original job.

\section{Securing rights in practice}

Research carried out for the Department for Work and Pensions and the Disability Rights Commission found that people with mental health problems had greater difficulties than others with disabilities in securing their rights in practice (Department for Work and Pensions \& Disability Rights Commission, 2004). Access to the tribunal process is beset with barriers, not least finding out that one has rights in the first place-especially for the $52 \%$ of disabled people who do not see themselves as disabled (including large numbers of people with mental health conditions) (Department for Work and Pensions, 2003). For them, even if they have heard of the Disability Discrimination Act, they assume it applies to wheelchair users and do not even seek advice on how to avail themselves of it (Department for Work and Pensions \& Disability Rights Commission, 2004).

This remains a major barrier for mental health service users. Mental health professionals have a significant role to play in alerting people to their rights.

\section{Case example 5: construction worker}

An applicant had worked for his employer in the construction industry for many years. He was off sick for 2 months with depression and during that time his employer contacted him to let him know that he had been made redundant. He went to see a psychiatrist, who advised him that he might have a strong Disability Discrimination Act case and recommended that he seek legal advice. The lawyer he consulted also thought that he had a case (Department for Work and Pensions \& Disability Rights Commission, 2004). 
If all mental health professionals were as well equipped to advise people when they may have a Disability Discrimination Act case, it would help spread awareness. In addition, a major awareness campaign by and for mental health service users on the reasonable adjustments that are possible, and how to negotiate for them, would be beneficial (Thornicroft, 2006).

\section{From individual redress to changing systems}

A key weakness of the Act is that an individual has to make a legal case after discrimination has occurred, and even then the outcome may be framed only in terms of equal treatment. The individual may actually need different treatment in order to achieve equal outcomes. Equalities and human rights legal experts have increasingly argued that classic equal treatment legislation is an inadequate mechanism to stimulate systemic change. Instead, one needs systemic interventions such as positive proactive duties to promote equality, or investigations into whole organisations or sectors. Individuals also need rights to positive change - not just formal equality. Disability discrimination law is a little better at this than gender and race law because of the concept of reasonable adjustments, requiring employers and service providers to adjust the environment (although only within what is 'reasonable') rather than treat everyone 'the same' (O'Brien, 2004).

Such a systemic vision is described by $\mathrm{O}^{\prime}$ Brien as a sea-change - a move away from an emphasis on individual victims, retrospective remedial litigation and individual redress, to the collective benefits for disadvantaged groups of systemic and active changes in policy.

\section{Formal investigations}

Formal investigations have the potential to dissect structural inequalities and recommend systemic solutions. The Disability Rights Commission was empowered by the Disability Rights Commission Act 1999 to conduct a formal investigation for any purpose connected with the performance of its duties under section 2(1) of the Act.

Those duties are:

- toworktowardstheelimination of discrimination against people with disabilities

- to promote the equalisation of opportunities for disabled people

- to take such steps as are considered appropriate with a view to encouraging good practice in the treatment of disabled people
- to keep under review the working of the Disability Discrimination Act 1995 and the Disability Rights Commission Act 1999.

Formal investigations can be undertaken into a single organisation (a named party investigation) or a sector (a general formal investigation).

\section{Physical health inequalities}

Between 2004 and 2006 the Disability Rights Commission ran a general formal investigation into physical health inequalities experienced by people with mental health problems and/or intellectual disability. Methods used included the most comprehensive study of primary care records and mental health issues in the world (8 million primary care records), coupled with studies in four areas of England and Wales, extensive consultation with service users and providers, evidence reviews, and written and oral evidence taken by a highlevel inquiry panel, which made recommendations designed to work in the newly configured NHS.

The investigation findings indicated that people with significant mental health problems experience a triple jeopardy: they are more likely to get major 'killer' diseases such as heart disease, diabetes and some cancers, more likely to fall ill with these diseases when young and, once diagnosed, more likely to die within 5 years (Disability Rights Commission, 2006b).

\section{Greater comorbidity and mortality}

The investigation confirmed that people with schizophrenia, bipolar disorder or depression have significantly higher rates of obesity, smoking, heart disease, hypertension, respiratory disease, diabetes, stroke and breast cancer than other citizens. It also made a completely new finding for the international literature: people with schizophrenia are almost twice as likely to have bowel cancer. They are also more likely than others to get illnesses such as stroke and coronary heart disease before the age of 55 . Once they have them, they are less likely to survive for 5 years.

All these facts mean that individuals with these mental disorders die younger than others. Social deprivation is one important factor but the differences cannot be explained by that alone. For almost all the key conditions studied, the 5-year survival rates were found to be lower for people with mental health problems than other groups (Hippisley-Cox et al, 2006a).

Despite these risk factors, people with mental health problems are less likely to be subject to the expected evidence-based checks and treatments. 
Although people with schizophrenia are more likely to have coronary heart disease and to die of it younger than other people, they are less likely to be screened or prescribed the evidence-based treatment such as statins. The report acknowledged that there is a need to raise awareness among general practitioners and consider ways in which this shortfall can be addressed (Hippisley-Cox et al, 2006b). Mental health service users experience diagnostic overshadowing, that is, physical health problems are viewed as part of their mental health problems and are not fully explored or treated.

\section{Access and attitudes}

The Disability Rights Commission investigation found that whereas mental health service users - and mental health practitioners - saw access difficulties as the responsibility of the service, primary care practitioners tended to see the problems as inherent to the individual (not attending because of a chaotic lifestyle or not understanding the 24-h clock). They simply did not seem to have made the jump to seeing access as the responsibility of the service provider. The report noted that in almost all interviews with primary care staff the researchers heard that mental health service users do not follow advice as given, do not attend appointments and cannot cope with the implications of the advice they are given. However, there did not seem to be any strategies in place to support these individuals in following the advice or guidance they received (Samele et al, 2006).

Where primary care did make reasonable adjustments these were often at no or low cost: for instance, where someone had a difficulty waiting in a crowded waiting room, the arrangement was that they waited in their car until called by the receptionist on their mobile phone.

\section{Recommendations and results}

The investigation also identified low expectations the attitude that people with mental health problems 'just do' die younger or 'just will not' participate in health services designed to improve physical health. In addition, it found non-compliance with the Disability Discrimination Act duties to make reasonable adjustments, and a lack of policy impetus and leadership to create change right through the health system.

The investigation made recommendations designed to challenge low expectations, give service users more power through information on rights, and give service providers and commissioners tools to support work to reduce these particular health inequalities. The recommendations range from the practical - enabling people to record their access needs on the patient record and then meeting them - to the strategic: for instance, assessing the physical health needs of people with mental health problems as part of local strategic needs assessments, commissioning new service models that meet the needs of the whole community and tracking over time whether important health outcomes such as the disproportionately high rate of early deaths from coronary heart disease are being reduced.

The formal investigation report was presented to the Secretary of State for Work and Pensions, the Secretary of State for Health and the Welsh Minister of Health in 2006. Progress in implementing the outcomes of the investigation was assessed by the inquiry panel in 2007 and it was hoped that thereafter health inspection bodies and the new Equality and Human Rights Commission would track progress. An initial response from the Department of Health in 2007 committed the government to strengthening commissioning for improved outcomes, although progress is yet to be assessed.

The investigation report includes recommendations for government and national bodies - for instance, ensuring that medical training promotes antidiscriminatory practice and explicitly addresses the risk of diagnostic overshadowing - and for service providers (the latter are shown in Box 5).

\section{Fitness for work}

In 2006 the Disability Rights Commission launched another formal investigation, into whether fitness standards required for people to work in nursing, social work or teaching discriminate against disabled people/those with long-term health conditions. This investigation will be significant to mental health service users. For instance, Peter van der Gucht, who had 17 years' experience of practising social work with a diagnosis of bipolar disorder, challenged a decision that because he had this diagnosis he should be subject to extra scrutiny and checks on his fitness to practise, even though no problems had occurred. The General Social Care Council withdrew the requirement in 2006. The Disability Rights Commission (2007c) concluded that the fitness standards could be used to discriminate - and recommended scrapping them. In 2007 the General Social Care Council agreed - and in 2008 the government is seeking ways to amend primary legislation to achieve this in relation to social work. This should mean that a diagnosis alone should not create a barrier to professional practice. Instead, the decision would have to be made case by case, on the basis of whether the person could actually do the job, with adjustments if required. 
Box 5 Recommendations of formal investigation on physical health inequalities

Mental health service providers

- Ensure through care plans that service users can access primary care to quality and outcomes framework standards

- Minimise and monitor the adverse effects of psychiatric medication, and revise medication accordingly. Ensure that people understand treatment options and can make active choices

- Include in-reach primary care services in contracts for in-patient psychiatric units

Learning disability service providers

- Produce health action plans for all people with intellectual disability

- Introduce health passports where these do not currently exist

- Ensure that antipsychotic medication is not used as a means of controlling behaviour

Mental health and learning disability service providers

- Positively promote healthy living for people living in the community, in residential and in in-patient settings. This will include:

- providing smoking cessation advice, support and interventions

- actively promoting a healthy diet

- advice and support with weight management

- encouragement and support to take exercise

- promoting a healthy environment, where people can easily have a healthy diet, exercise and live smoke-free

- Provide support to ensure that physical health needs are appropriately addressed within primary care

(Disability Rights Commission, 2006b)

\section{Conclusions}

People with mental health problems experience inequality, discrimination and social exclusion in a range of important dimensions, including home life, personal and intimate relationships, work and employment, leisure and recreation, travel, insurance and financial services, debt, entitlements and citizenship, physical vulnerability, health and healthcare (Thornicroft, 2006).

British equalities legislation has evolved over the years and has incorporated both a formal equality principle (prohibiting differences in the treatment of people on the grounds of their social identity characteristics) and a substantive equality principle (establishing equality with respect to what people can do and be). This latter principle has been influential in the revision of the Disability Discrimination Act 2005, which includes a positive equalities duty. The Equalities Act 2006 explicitly recognises that in order to avoid discrimination and ensure equality in practice it is necessary to consider the varying needs of different individuals and groups, including those with disabilities.

Theinclusion of people with mental health problems in the coverage of disability discrimination law has outlawed discrimination and had some impact in terms of cases concluded, formal investigations completed and use of the legal framework as a basis for positive practice by employers, service providers and other organisations. This has implications for mental health practice. It also suggests potential for future use of legal powers to further promote equality and human rights. For example, formal investigation into physical health inequalities could be followed by investigations into other areas of inequality such as insurance, decisions on parenting and child care proceedings, or disadvantage in the acquisition of skills.

The equalities and human rights field is rapidly changing, with single equalities law expected in 2008-9 and the Equality and Human Rights Commission replacing the role of the Disability Rights Commission and other equality commissions. This creates new opportunities to highlight and tackle discrimination on mental health grounds within a broader set of developments in social justice. It will be important that this endeavour benefits from mental health expertise.

\section{Declaration of interest}

None.

\section{References}

Barnes, C. (1991) Disabled People in Britain and Discrimination: A Case for Anti-Discrimination Legislation. Hurst.

Boardman, J. (2003) Work, employment and psychiatric disability. Advances in Psychiatric Treatment, 9, 327-334.

Bunt, K., Shury, J. \& Vivian, D. (2001) Recruiting Benefit Claimants: Qualitative Research with Employers in ONE Pilot Areas (Research Series Paper No. 150). Department for Work and Pensions.

Cabinet Office (2007) Fairness and Freedom: The Final Report of the Equalities Review. TSO (The Stationery Office).

Department for Communities and Local Government (2007) Discrimination Law Review. A Framework for Fairness: Proposals for a Single Equality Bill for Great Britain. A Consultation Paper. DCLG.

Department for Work and Pensions (2003) Disabled For Life? Attitudes Towards, and Experiences of, Disability in Britain. DWP.

Department for Work and Pensions \& Disability Rights Commission (2004) Monitoring the Disability Discrimination Act 1995: Phase 3. DWP.

Department of Health (2002) Mental Health and Employment in the NHS. Department of Health. 
Disability Rights Commission (2003a) Coming Together - Mental Health Service Users and Disability Rights. DRC.

Disability Rights Commission (2003b) Disability Equality: Making it Happen. First Review of the Disability Discrimination Act 1995. DRC.

Disability Rights Commission (2006a) Definition of Disability within Anti-discrimination Law: Recommendation to Government, July 2006. DRC.

Disability Rights Commission (2006b) Equal Treatment: Closing the Gap. A Formal Investigation into Physical Health Inequalities Experienced by People with Learning Disabilities and/or Mental Health Problems. DRC.

Disability Rights Commission (2007a) The Disability Agenda. Creating an Alternative Future. DRC.

Disability Rights Commission (2007) Maintaining Standards, Promoting Equality: Professional Regulation and Disabled People's Access to Careers in Nursing, Teaching and Social Work. DRC.

Disability Rights Commission (2007b) Coming Together - Mental Health Service Users, Equality and Human Rights. DRC.

Egan, J. (2005) Managing disability at work: the 2005 IRS survey. IRS Employment Review, issue 835

Employers' Forum on Disability (1998) Practical Guide to Employment Adjustments for People with Mental Health Problems. Employers' Forum on Disability.

Equal Opportunities Review (2002) Managing disability. Equal Opportunities Review, 96, 762.

Freud, D. (2007) Reducing Dependency, Increasing Opportunity: Options for the Future of Welfare to Work. An Independent Report to the Department for Work and Pensions. Department for Work and Pensions.

Hippisley-Cox, J., Vinogradova, Y., Coupland, C., et al (2006a) A Comparison of Survival Rates for People with Mental Health Problems and the Remaining Population with Specific Conditions. Disability Rights Commission.

Hippisley-Cox, J., Parker, C., Coupland, C., et al (2006b) Use of Statins in Coronary Heart Disease Patients with and without Mental Health Problems. Disability Rights Commission.

HM Government (2004) Fairness for All: A New Commission for Equality and Human Rights (White Paper). TSO (The Stationery Office).

HM Government (2006) A New Deal for Welfare: Empowering People to Work (Green Paper). TSO (The Stationery Office).

Ikkos, G., Boardman, J. \& Zigmond, T. (2006) Talking liberties: John Rawls's theory of justice and psychiatric practice. Advances in Psychiatric Treatment, 12, 202-210.

Mind (1998) Public Attitudes to Mental Distress. Mind.

O'Brien, N. (2004) 'Accentuating the Positive': Disability Rights and the Idea of a Commission for Equality and Human Rights. Industrial Law Society (http://www.industriallawsociety. org.uk/papers/obrien-full.htm)

Oliver, M. (1990) The Politics of Disablement. Macmillan.

Royal Association for Disability and Rehabilitation (2007) Doing Work Differently. RADAR.

Samele, C., Seymour, L., Morris, B., et al (2006) A Formal Investigation into Health Inequalities Experienced by People with Learning Difficulties and People with Mental Health Problems - Area Studies Report. Disability Rights Commission.

Sayce, L. (2000) From Psychiatric Patient to Citizen. Overcoming Discrimination and Social Exclusion. Macmillan.

Sayce, L. \& Boardman, J. (2003) The Disability Discrimination Act 1995: implications for psychiatrists. Advances in Psychiatric Treatment, 9, 397-404.

Social Exclusion Unit (2004) Mental Health and Social Exclusion. Office of the Deputy Prime Minister.

Thornicroft, G. (2006) Shunned. Discrimination against People with Mental Illness. Oxford University Press.

Waddell, G. \& Burton, A. K. (2006) Is Work Good for Your Health and Well-being? TSO (The Stationery Office).

Archibald v. Fife Council [2004] ICR 954, HL; [2004] UKHL 32.

Jones v. The Post Office [2001] EWCA Civ 558; [2001] ICR 805.

Jones (Appellant) v. 3M Healthcare Limited (Respondents) and three other actions [2003] UKHL 33.

Meikle v. Nottinghamshire County Council [2005], ICR 1; [2004] EWCA Civ 859

Morgan v. Staffordshire University [2002] ICR 475, EAT.

Power v. Panasonic UK Ltd [2003] IRLR 151, EAT.

\section{MCQs}

1 The Disability Discrimination Act:

a was passed by the Scottish Parliament in 1975

b was amended in 1995

c covers people with any form of illness lasting more than 6 weeks

d requires employers to take on anyone with a physical disability

e requires employers to make reasonable adjustments in the workplace for people with disabilities.

2 The Disability Discrimination Act:

a covers protection for discrimination in employment

b makes it legal for an employer to treat someone with a disability less favourably than those without

c relating to mental illnesses covers only long-term psychotic disorders

$\mathrm{d}$ does not allow for positive discrimination in favour of disabled people

e means that disabled people can always be debarred from employment on health and safety grounds.

3 In the Disability Discrimination Act:

a transport is not covered

b only further and higher education are covered

c the NHS is exempt

d only large private companies are included

e it is illegal for supermarkets to treat someone less favourably for a reason related to their disability.

4 The 2005 amendments to the Disability Discrimination Act include:

a a Disability Equality Duty for public sector bodies

$b$ the requirement that mental health conditions are 'clinically well-recognised'

c a comprehensive list of all reasonable adjustments that must be made

$\mathrm{d}$ a requirement that people with mental health conditions must be disabled for more than 2 years

e the creation of the Disability Rights Commission.

5 The Equality and Human Rights Commission:

a covers all countries in the European Union

b was established in 2000

c does not concern itself with gender equality

d will promote human rights only in low- and middleincome countries

e was established through the Equalities Act 2006. 